\title{
Enhancing The Quality And Accessibility Of Geographic Learning Through Modern Instructional Strategies In The School: Its Implications And Opportunities
}

\author{
Reshma.C.U *, Sheheersha.S.K*, Dr.V.Saravanabavan** \\ * Research Scholars, ** Assistant Professor, Department of Geography, School of Earth and Atmospheric \\ Sciences, Madurai Kamaraj University, Madurai, Tamilnadu, India \\ reshmageography@gmail.com
}

\begin{abstract}
Geography is the study of the interaction between people and environment.It develops knowledge and understanding of the distribution of human and natural phenomenas. Now Geography teachers use an inquiry based approach, innovative techniques and broad based curriculum to the learning which extends children's awareness of the wider world beyond the local area. Modern instructional strategies develops competencies essential in the workplace and leads to careers in areas such as spatial sciences, resource management and urban planning. Nowadays geography caters for a variety of learning styles such as verbal linguistics, visualspatial, logical-mathematical, bodily-kinesthetic, and interpersonal and intrapersonal. These include maps, tables, photographs, graphs, diagrams, satellite images, field work report, annotated visual displays, oral presentations, debates, discussions, essays, structured questions, ICT databases, software packages and GIS analysis. A sound geographic background provides a sense of location (place)of distribution(space)of people and processes (movement),interactions and associations, spatial changes overtime and of scale (local,natioal,regional,global).The main objective of the study is to analyse the impact of modern instructional strategies and provide a set of suggestions for new geography curriculum. By analyzing primary informations we can understand the depth of practical knowledge of students and implications of geography learning in the day to day life situations. The study is mainly based on primary questionnaire survey which is concreted by secondary information obtained from journals. The primary data obtained from 200 students. It is based on random sampling. Simple statistical methods used for analysis.
\end{abstract}

Key Words: Modern instructional strategy-Inquiry based approach- Broad based curriculum - Modern pedagogy - Learning implication

\section{Introduction}

Geography is the science which deals with the aerial differentiation and spatial distribution of various elements on the earth's surface. The geography itself has been divided in to different disciplines such as physical geography, human geography, bio-geography etc. Human Geography deals with the study of the interaction between people and environment .It develops knowledge and understanding of the distribution of human beings and natural phenomenas. Now Geography teachers use an inquiry based approach to learning drawing on research, practical activities and fieldwork. Innovative techniques and broad based curriculum extends children's awareness of the wider world beyond the local area. Modern instructional strategies develops competencies essential in the workplace and leads to careers in areas such as spatial sciences, resource management and urban planning. Nowadays geography caters for a variety of learning styles such as verbal linguistics, visual-spatial, logical-mathematical, bodily-kinesthetic, interpersonal and intrapersonal. These include maps, tables, photographs, graphs, diagrams, satellite images, field work report, annotated visual displays, oral presentations, debates or discussions, essays or structured questions, ICT databases, and other software packages, GIS analysis. A sound geographic background provides a sense of location (place)of distribution(space) of people and processes (movement),interactions and associations, spatial changes overtime and of scale (local,natioal,regional,global).

\section{Objectives:}

- To analyze the importance of the utilization of modern instructional strategies in teaching geography.

- To find out the importance of co-curricular activities in geography teaching -learning.

- To understand the implications of geography learning in the day to day life situations.

- To suggest suitable instructional strategies appropriate for the effective teaching of geography. 


\section{Methodology:}

The study is mainly based on primary questionnaire survey which is concreted by secondary information obtained from journals. The primary data obtained from 200 students. It is based on random sampling. Simple statistical methods used for analysis. Graphical methods used for representing the data.

\section{Instructional Methods:}

In any pedagogical practice the teacher engineers makes the learning environment through his skillful, tactical and technical ways of imparting the knowledge in to the learners. These ways are called teaching methods.( Gertler 2000) Therefore, teacher as the initiator of the instructional communication process should carefully select appropriate teaching methods techniques or strategies that will suit the learning environment for the effective teaching learning process to take place. Such methods include; discussion method, project method, inquiry method, lecture method, questioning, activity method, field trip method, and laboratory techniques.

The teaching of geography laid more emphasis on the following:

- The description of the physical features in their locality.

$\circ$ The people living in their area.

- The type of settlements and food they eat.

- The land use analysis, types of soils and crop.

- The comparisons of the resources of the area with those of other areas.

Local geography inculcates in the learners such skills as critical reasoning, sound judgement, keen observation, data collection techniques and analyses which are crucial in the learners' academic endeavours and infact in other human endeavours, learners are more exposed and familiar with their immediate environment. Opportunities for employment are enhanced. Since local geography exposes learners to the political, economic and socio-cultural aspects of their locality, their productivity or efficiency are enhanced and thus prepared and made versatile for the labour market. Geography learning provides provision for training in good citizenship.

\section{Scope Of School Geography:}

The scope of school geography is very wide. At the junior secondary school, social studies are taught as geography. Relevant geographical topics that are related to the immediate environment of the learners are incorporated in the subject. Man-environmental relationship is the basic concept of the study at this level. At the secondary school level the nature of geography is compartmentalized as, human, regional and map work. The teaching of geography at this level is centered mainly on man's interaction with his environment. Infact branches of geography have complexity in nature. Sometimes it includes economic geography, agricultural geography, bio-geography, settlement geography, medical geography, climatology, geomorphology, aerial photography, GIS and so on.

\section{Geography Curriculum Special Features:}

Geography is versatile, expressive, creative, problem solving practical and intellectually stimulating school subject. (Chalkley 1993) The distinctive characteristics of geography, i.e., central concepts, logical internal structure, methodology, integrative nature, transparent interdisciplinary effects make it an integral part of any worthwhile school curriculum. Consequently, geography should remain a core subject in the senior secondary school curriculum. Geography affords plenty of instances in which critical thinking, problem solving, inductive approaches etc can be exercised to generate pupil's interest and participation and enhance effectiveness and efficiency in teaching -learning situations.

(1) The provision of a geography programme that is based on the choice of suitable and relevant themes. Units, content, teaching methods, student's activities, teaching aids and evaluation.

(2) The reduction in the scope and content coverage of the subject matter of senior secondary school geography without losing the high quality required at that level.

(3) The provision of a wide range of experience for students in the use of the concept-centered approach to learning, problem solving and activity based techniques for the acquisition of basic geography knowledge and skills.

(4) The inclusion of innovative elements in to the syllabus through the emphasis placed on practical geography.

\section{Analysis And Interpretation:}

The questionnaire includes 38 pre designed questions. For the analysis of the study it can be divided in to four sections. That is first twenty questions deals with the geography learning, next section belongs to general awareness about geography, third section includes the questions related with motivation, and the last section 
deals with co-curricular activities in teaching geography. The entire analysis made with the help of responses from the students. The analysis was graphically represented for further reading.

\section{Responses on geography learning:}

All the students are very much interested in learning geography. But only $45 \%$ of them get motivated by the teaching learning process adopted by their by their geography teacher. All the students prefer teaching geography by using variety of teaching aids. But $65 \%$ of them are not satisfied by the use of learning aids. They mentioned that geography teachers still use historical methods for teaching geography.

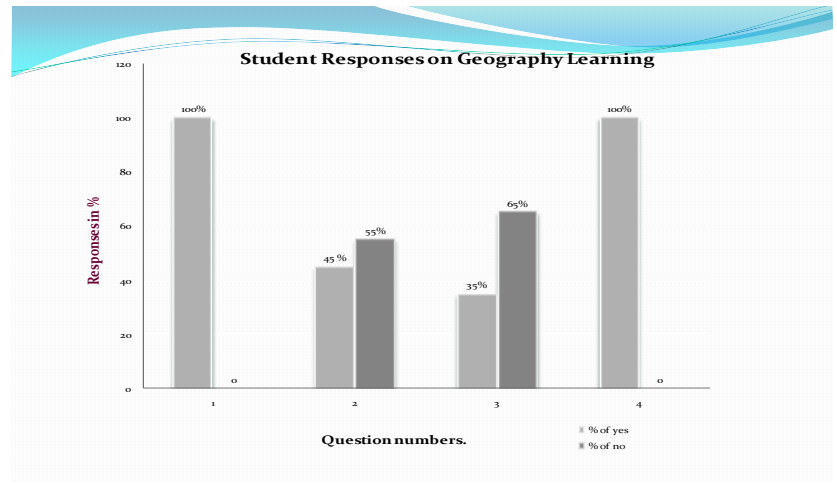

\section{Responses on classroom instruction:-}

All the students interested in learning geography through modern instructional strategies. About $70 \%$ of the students mentioned that there are no seminars in their classes and they have interested in doing assignments, projects and seminars as a part of geography learning. $55 \%$ of the students mentioned that their teacher always using assignment method for teaching geography. $90 \%$ of the students agreed that class tests will helps in better understanding and also get motivation through it. But $75 \%$ of them are not satisfied with the frequency of class tests.

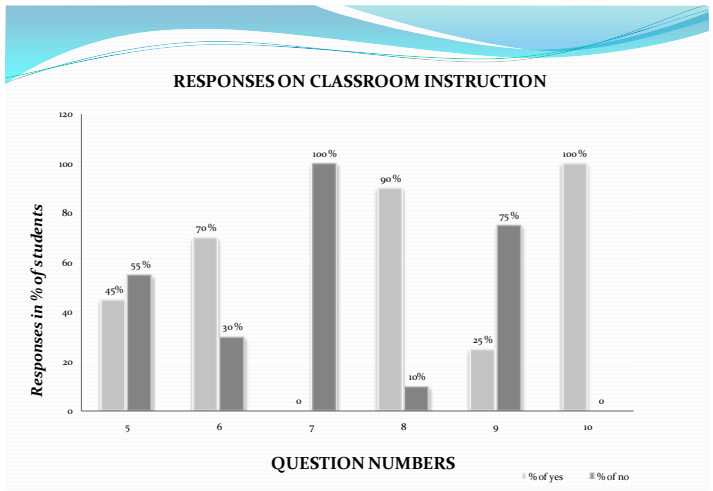

\section{Responses on co-curricular activities:-}

In questions regarding co-curricular activities in teaching learning in geography, all the students have interested in participating in social science exhibitions. Majority of them presented items in the exhibitions. They have more interests in participating club activities. All the schools have social science clubs. All the students are members of social science clubs. But $80 \%$ of the students mentioned that there is no adequate time for club activities because of tight class time. 


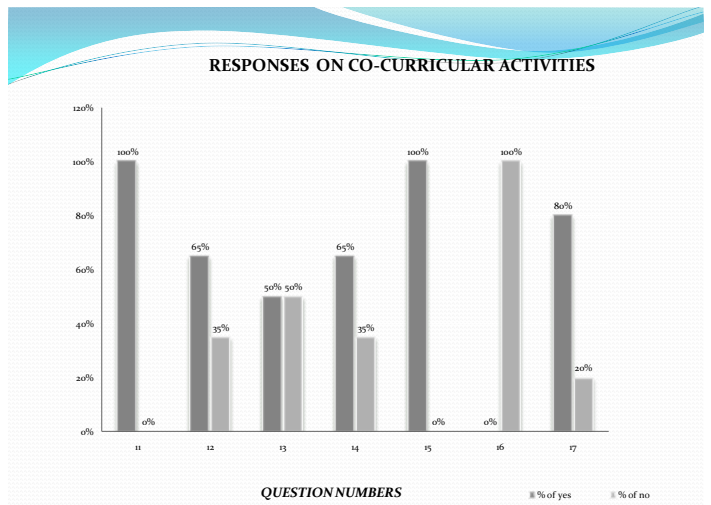

\section{Responses on reference material:-}

$45 \%$ of the students prefer library references for learning geography. Only $30 \%$ of the students use internet facilities for geography learning. Most of them interested in learning geography through maps, charts, atlases, globes and pictures. But most of them do not know about topographical maps.70\% of them agreed that geography learning helps them to develop preservation and conservation values and more practical experiences for the better life.

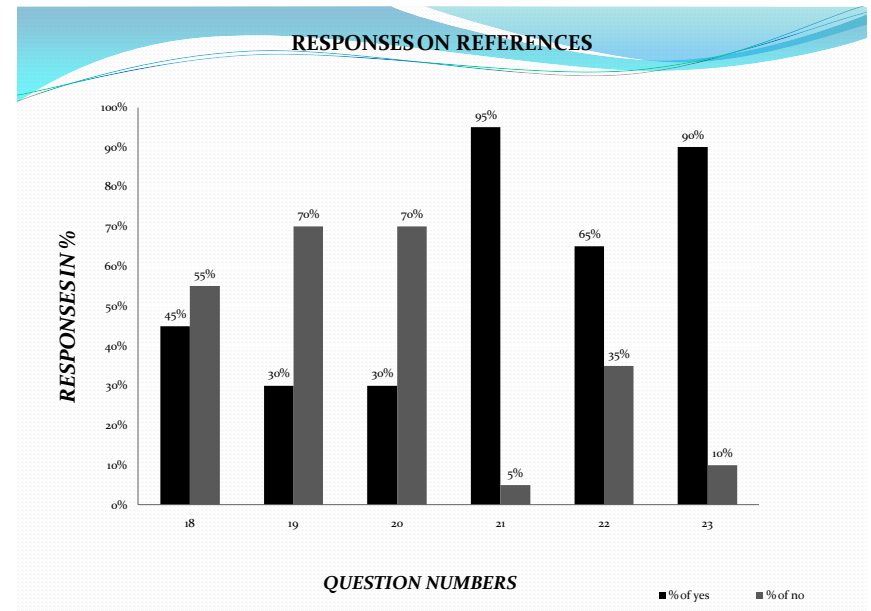

From the responses we can understand that all the students are very much interested in learning geography. All the students have the same opinion that geography learning provide more practical experiences, geography learning helps to lead better life and man-environmental relationship can be well understood through geography learning. $75 \%$ of students agree that their teacher correlates the content material with that of local resources and daily life.95\% of the students agree that future oriented outlook is vital for better understanding of the geographical facts. $35 \%$ of the students not visited any places as a part of geography learning.

\section{Responses on need for learning geography}

From the responses we can understand that all the students are very much interested in learning geography. All the students have the same opinion that geography learning provide more practical experiences, geography learning helps to lead better life and man-environmental relationship can be well understood through geography learning. $75 \%$ of students agree that their teacher correlates the content material with that of local resources and daily life. $95 \%$ of the students agree that future oriented outlook is vital for better understanding of the geographical facts. $35 \%$ of the students not visited any places as a part of geography learning.

$70 \%$ of them agreed that geography learning helps them to develop preservation and conservation values and more practical experiences for the better life.75\% of the students agree that geography learning helps to develop social qualities and values. $80 \%$ of the students answered that geography learning through problem solving method should be stressed and physical geography is vital for the better understanding of human geography. All students supported that map study helps a lot in reading and locating features. In questions regarding general awareness about geography, $70 \%$ of the students have an idea about their nearest national highway. They have a little idea about the precautions to be taken for the earthquake. $90 \%$ of the students has an idea about Dengue fever and its prevention. 


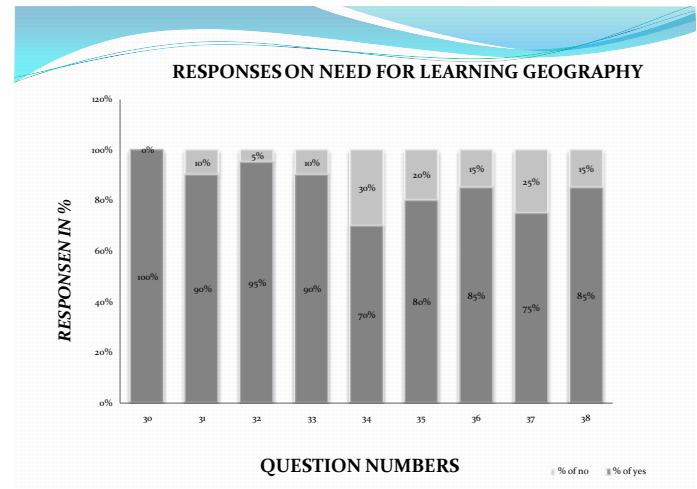

Findings:

- All the students are very much interested in learning geography.

- Most of the students prefer geography learning through modern instructional aids.

- Most of them have interested in co-curricular and club activities.

- All the students prefer geography learning with the help of maps, charts, pictures, atlases, models globes etc...

- Through the proper geography learning, it is easy to understand the man -environmental relationship and it also develops values, skills and interests in geography.

- To lead a better life, the knowledge about geography is necessary.

- Geography knowledge is essential for the conservation and preservation of values.

\section{Recommendations For Implementation In Schools:}

- Exposure of geography teachers to the new Curriculum through the organization of workshops and seminars at various strategic centres in the country before and during the first few years of implementing this curriculum. The central and state government and their agencies should provide support system to sustain the programme and monitor its progress.

- Government should provide adequate funding to the schools. So that geography as a core subject should have the basic equipment and materials that would enhance its teaching.

- The laboratory should be equipped with furniture designed for practicals and storage of materials like maps, rock specimen, models, tapes, surveying chains, prismatic compass etc.

- The writing of a new set of textbooks based on a new geography curriculum should be encouraged. In addition, copies of journals and magazines on geography and geographical education should be made available to teachers in the schools.

- Similarly, an inventory of the basic teaching aids and their sources including improvised types should be made available to schools. Most of these basic teaching aids have been identified at appropriate places in this programme.

- The implementation of an expert committee for administering the continuous assessment of pupils.

- Efforts have to be made by geography teachers to encourage an annual rise in the enrolment of student for geography at the senior secondary level through improvised methods of teaching, enthusiasm and patience.

- In view of the fact that geography is a highly versatile subject allowing a variety of combinations for university based, professional courses. (Architecture, urban and regional planning, estate management, land surveying, military studies, business administration).

- Last but not least Geography should separate from the curriculum of social science.

\section{Suggestions For Teachers:}

- Reinforce and motivate the learners towards the achievement of the objectives stated for the lesson.

- Stimulate the learner's interest by presenting the instructional materials in appealing manner

- Learner should be included in problem solving activities.

○ Be learner - centered in teaching

- Make use of appropriate, quality and suitable instructional media in teaching.

- Always proceed from simple to complex, known to unknown, concrete to abstract, observation to reasoning.

- Integrate system approach in the planning and delivery of the lesson. 
- Acquire competency in the use of teaching skills such as set of introduction, stimulus variation, questioning, use of illustrations and examples, non verbal communication and closure skills among others.

\section{Suggestions For Approaches:}

$\circ$ Outdoor approach: This involves taking learners out to see things for themselves because seeing is believing.E.g: study tour, field trip.

○ Teaching should be localized: Teaching should be localized in terms of materials utilised.E.g: soil types, rock types, clothing, food items, paintings and photographs.

- Learner centered curriculum: motivation makes the student more perfect. It includes inquiry method, project method, laboratory techniques etc.

○ Field work: this provides critical thinking orientation in scientific observation, skills in recording, measuring and map drawing or making, which all constitute the foundation for data collection and analysis.

○ Map work: Map is the essential tool for geographers. It involves map reading, interpretation, elementary surveying and introduction to aerial photography at secondary school level.

\section{Conclusion:}

School courses in geography have traditionally emphasized the learning of the established factual content of the subject. However, this conventional approach is now being challenged by several influences. Perhaps the most important of these factors are recent advances in geographical research, a growing understanding of the nature of scientific inquiry and a belief that, in our rapidly changing world, styles of learning are ultimately more important than facts. In response to these influences the teaching of geography in schools is gradually and cautiously changing

\section{References:}

[1]. Algeo, K.2007, Teaching cultural geography with "Bend it like Beckham" Journal of Geography; 106, 3, 133-143

[2]. Chalkley, B., Fournier, E. J., \& Hill, D.2000, Geography teaching in higher education: Quality, assessment, and accountability Journal of Geography in Higher Education; 24, 2, 238-245

[3]. Dalton R. T: 2001, the fieldwork experiences of undergraduates on entry into higher education Journal of Geography in Higher Education; 25, 3, 379-393

[4]. Delyser, D, 2003, Teaching graduate students to write: A seminar for thesis and dissertation writers Journal of Geography in Higher Education; 27, 2, 169-181

[5]. Gertler, M. S.2003, Tacit knowledge and the economic geography of context, or the undefinable tacitness of being (there) Journal of Economic Geography; 1, 75-99

[6]. Goett, J. A., \& Foote, K. E.2000,Cultivating student research and study skills in web-based learning environments Journal of Geography in Higher Education; 24, 1, 92-99

[7]. Healey, M.2003, Promoting lifelong professional development in geography education: International perspectives on developing the scholarship of teaching in higher education in the twenty-first century.Professional Geographer: The Journal of the Association of American Geographers, 55, 1, 1-17

[8]. Hill, J., \& Woodland, W.2002, An evaluation of foreign fieldwork in promoting deep learning: A preliminary investigation Assessment \& Evaluation in Higher Education; 27, 6, 539-555

[9]. Jain, C., \& Getis, A.2003, The effectiveness of Internet-based instruction: An experiment in physical geography. Journal of Geography in Higher Education; 27, 2, 153-167

[10]. Jenkins, A.2000, The relationship between teaching and research: Where does geography stand and deliver? Journal of Geography in Higher Education; 2000, 24, 3, 325-51 